\title{
LA CARTA Y EL PAPEL EN LA COMEDIA DE CAPA Y ESPADA DE CALDERÓN: GÉNERO, ENREDO Y SUSPENSO
}

\author{
Omar Alejandro Higashi Díaz \\ Universidad Autónoma Metropolitana / Iztapalapa \\ Filología Medieval, Áurea e Hispanoamericana \\ de los Siglos XVI al XVIII \\ Av. San Rafael Atlixco 186, Col.Vicentina \\ C.P.09340, Del. Iztapalapa \\ México D.F \\ higa@xanum.uam.mx
} [Anuario calderoniano (ISSN: 1888-8046), 6, 2013, pp. 183-198]

La carta fue un accesorio escénico de reducidas proporciones fisicas, pero con importantes consecuencias estructurales en la comedia de capa y espada calderoniana. Si a primera vista parece unidimensional, el análisis detenido de sus distintas apariciones en la comedia demuestra una complejidad que va desde la sencilla carta de presentación («Leed. Sabréis della quien soy / y mi pretensión después», dice don Pedro de Lara en No siempre lo peor es cierto ${ }^{1}$ ) o la confesión

${ }^{1}$ Calderón, No siempre lo peor es cierto, II, vv. 485-486. Cito todas las obras por la base de datos de M. ${ }^{a}$ del C. Simón Palmer (dir.), Teatro Español del Siglo de Oro 3.0. 
que puede perjudicar de caer en las manos equivocadas ("y no es discreto un papel, / sino en manos de su dueño", advierte doña María a doña Ana, en Bien vengas mal, cuando le confia las cartas de amor que ha intercambiado con don Juan ${ }^{2}$ ), hasta el informe de una infidelidad cometida a la distancia ("la carta dirá mejor / su traición y mi cuidado $\left.»^{3}\right)$ o aquella que inocentemente fomenta el enredo de ser entregada a un destinatario equivocado ( Viven los Cielos, / que porque todo se yerre, / dio el papel a don Gutierre» $\left.{ }^{4}\right)$. Su riqueza deriva del carácter estructural y efectista que se le ha concedido en varias tramas calderonianas: recordemos la didascalia inicial de Con quien vengo, vengo ("Salen Lisarda, $y$ Leonor asidas de un papel $\rangle^{5}$ ) y el enredo que se desata por ese billete; la Violante de También hay duelo en las damas que sale al tablado "con un papel en la mano» y una criada detrás que le acerca dos bujías para poder leer su carta otras mil veces sólo para su deleite ${ }^{6}$; o cómo doña Beatriz y doña Leonarda se disputan una carta en No hay burlas con el amor hasta que al final la rompen, como eje de la intriga; o cuando don Toribio Cuadradillos, en un tono muy distinto, se excusa de leer una invitación, por no saber, para que Clara y Eugenia no asistan a la recepción de la reina, aunque considera que podría aceptar dentro de dos años, el tiempo que puede durar su aprendizaje de la lengua escrita ${ }^{7}$. Al revisar la bibliografia crítica sobre un corpus de comedias de capa y espada calderonianas escritas entre 1627 y 1637 (pienso en Hombre pobre todo es trazas de 1627, La dama duende y Casa con dos puertas, mala es de guardar, ambas de 1629, Con quien vengo, vengo de 1630, Mañanas de abril y mayo de 1633, El galán fantasma de entre 1634-1636, Bien vengas mal si vienes solo de 1635, El escondido y la tapada de 1636 y No hay burlas con el amor de $1637^{8}$ ), queda la sensación de que el billete o la carta amorosa no han llamado

Modernizo grafias, regularizo acentuación y modifico la puntuación en todos los casos.

2 Calderón, Bien vengas mal, I, vv. 469-470.

3 Calderón, No siempre lo peor es cierto, I, vv. 644-645.

${ }^{4}$ Calderón, Primero soy yo, III, vv. 699-671.

5 Calderón, Con quien vengo, vengo, I, v. 1.

${ }^{6}$ Calderón, También hay duelo en las damas, vv. 1 acot. y 1-7.

7 Calderón, Guárdate de la agua mansa, III, vv. 164-186.

${ }^{8}$ Los resultados de este trabajo serían menos precisos y se hubieran obtenido más penosamente sin la ayuda de los buscadores de la base de datos en M. ${ }^{a}$ del C. Simón Palmer (dir.), Teatro Español del Siglo de Oro 3.0. 
poderosamente la atención, quizá por encontrarse diluidos en la trama, salvo por la carta paródica redactada en fabla de La dama duende ${ }^{9}$. Con una perspectiva de conjunto, en fecha reciente ha tratado el tema Sebastian Neumeister, lo que garantiza su pertinencia ${ }^{10}$.

La carta no siempre es carta de amores y genera enredos, sino que su designación se reparte entre la carta (una misiva, a ratos sinónimo de pliego, con ciertas convenciones: comunicar a dos interlocutores distantes por un intermediario y estar siempre firmada), el papel (escrito de tono más espontáneo, formato más discreto, muchas veces anónimo) y el billete (semejante al papel, pero de poco uso en el argot calderoniano $\left.{ }^{11}\right)$.

En la comedia de capa y espada, la importancia de la carta es reducida e indica, en todos los casos, una comunicación a distancia, de carácter formal (contra las convenciones del papel), por un intermediario, que pocas veces genera un enredo. Hombre pobre todo es trazas inicia, por ejemplo, con la carta que lleva don Diego, enviada por su padre a don Luis de Toledo con una letra de cambio por apenas 400 reales $^{12}$; si hay enredo, es más por inflar el monto de la letra de cambio que por la carta misma. En El escondido y la tapada, César recibe una carta o pliego de Celia, enviada de Madrid a Lisboa por medio de una estafeta ${ }^{13}$; esta carta (que no genera enredos más allá de traerlo de nuevo a Madrid) tiene su paralelo en la que recibe Félix cuando se haya en Italia, de alguno interesado en el honor de su casa, al pedirle vuelva para hacer coincidir en Madrid a los dos personajes ${ }^{14}$.

El verdadero valor de la carta hay que buscarlo, sin embargo, fuera del género; en una comedia palaciega semi-histórica como Para vencer a amor, querer vencerle, en donde el desdén de Margarita hacia César Colona tiene razones políticas en el contexto de sucesión del ducado de Ferrara y se presenta como personaje, entre otros rasgos de oficialismo, al mismo Sacro Emperador Romano Federico III. Ahí, la carta se distingue por su formato oficial (un «pliego» con el nombre del destinatario encima y "que con real sello / viene cerrado»; se trata de

\footnotetext{
${ }_{9}^{9}$ Por ejemplo, Escalonilla López, 2002, pp. 152-153 y Arellano, 2006, p. 192.

${ }^{10}$ Neumeister, 2011.

11 De las comedias analizadas, sólo se usa en La dama duende, I, vv. 939 y 1082.

12 Calderón, El hombre pobre todo es trazas, I, vv. 121, 125, 249, 483 y 487.

13 Calderón, El escondido y la tapada, I, vv. 39- 43, 252-255 y 885.

${ }^{14}$ Calderón, El escondido y la tapada, I, 621-624.
} 
una carta de presentación de César Colona que más bien anuncia su falsa muerte ${ }^{15}$ ) y, en la segunda jornada, la carta que escribe Margarita a Celio, carta autógrafa y firmada ${ }^{16}$, corrobora la sucesión del ducado de Ferrara, a la espera de la ratificación del Sacro Emperador Romano. La redacción de la carta debe ser más atenta y fría que la carta familiar, pues versos después la misma Margarita se presenta en escena escribiendo una carta, que empieza y rompe dos veces, hasta que Flora le dice «imagino / que haces alguna comedia / y vas, de miedo del silbo, / descartando borradores» ${ }^{17}$; no tiene Margarita miedo del silbo, sino de dejar que asomen sus sentimientos («maldigo, / que aquí el agradecimiento / parece de amor indicio» ${ }^{18}$ ), así que al final se decide a escribir en tercera persona ${ }^{19}$. Ninguna de las dos cartas fomenta el enredo, aunque la primera de ellas resulta fundamental para que César pueda ocultar su identidad bajo el nombre de Celio y Margarita entonces ceda a su amor bajo esta nueva identidad, liberada de la responsabilidad del gobierno. La segunda carta sirve para evidenciar con sutileza la lucha que libra Margarita en su interior respecto a Celio.

Así, por la naturaleza de los referentes de la comunicación escrita, este accesorio escénico ofrece indicios para la identidad genológica de las comedias, pues si bien la carta existe indistintamente en varios marcos, dentro de la comedia palaciega de tema histórico merece una tratamiento más oficial (de ahí la denominación de carta o pliego) que en la comedia de capa y espada o que en la tragedia, donde el papel es un medio privilegiado de comunicación y generador de enredos. Por el contrario, pocos enredos pueden nacer de una carta oficial escrita en un pliego, de tamaño visible, al contrario del discreto papel. No se encontrarán, por otro lado, cartas o pliegos en la tragedia calderoniana o en la comedia mitológica; pero sí papeles capaces de generar intrigas completas y, en casos como el de El mayor monstruo del mundo, responsables en buena medida de la tensión dramática al demorar la lectura de las fatales noticias que contiene, como ha demostrado

15 Calderón, Para vencer a amor, querer vencerle, I, vv. 1085-1092; se le denomina carta en I, vv. 1078 acot., 1110 acot. y v. 1112.

16 Calderón, Para vencer amor, querer vencerle, II, vv. 235-236; se le denomina carta en II, vv. 227 y 232 acot.

17 Calderón, Para vencer amor, querer vencerle, II, vv. 722-725.

18 Calderón, Para vencer amor, querer vencerle, II, vv. 706-708.

19 Calderón, Para vencer amor, querer vencerle, II, vv. 742-743. 
Sebastian Neumeister ${ }^{20}$. En los autos sacramentales, el papel se percibe siempre con un valor simbólico muy ajeno al enredo, del tipo «en papel sellado, / con uno de siete sellos, / que algún venturoso día / serán siete sacramentos» ${ }^{21}$ o en «sellado papel / de siete sellos» ${ }^{22}$ (en alusión al libro de la $v^{2} a^{23}$ ), transmite alguna cita vétero o neotestamentaria («Vase, dándole un papel, y le abre Baltasar y le lee. Así habla en un proverbio / del Espíritu la voz: / polvo fuiste y polvo eres / y polvo has de ser» ${ }^{24}$; «Pobre Lee, y lo verás. / Lee Hombre Ciento por uno tendrás, / si das limosna. Mateo» ${ }^{25}$; «Engañaste, que no es / el papel que a mirar llegas / sino una epístola, que / del mayor misterio llena, / escribo a los de Corinto» $\left.{ }^{26}\right)$; la carta, por otro lado, sólo tiene una existencia excepcional (una vez como carta de presentación ${ }^{27}$ y otra como finiquito y carta de pago ${ }^{28}$ ). En la comedia de santos, la carta y el papel tienen un peso simbólico extraordinario («Pluma será este puñal, / papel este lienzo blanco / y tinta para escribirlo / la sangre es ya de mis brazos $\left.»^{29}\right)$, pero tampoco generan intrigas.

Dentro de la comedia de capa y espada, de tendencia costumbrista, domina por su influencia y variedad de usos el papel o billete muy por encima de la carta, de presencia contenida. La variedad de sus funciones obliga a distinguir entre la función mimética del papel y su función dramática. Aunque resulta difícil disociarlas en la práctica escénica, considerar mayor inclinación hacia uno u otro lado nos permite subrayar su posición secundaria, como un motivo más dentro de la intriga, o principal, como generadora de intrigas. Si se atienda a su importancia, se puede advertir que el papel con una función mimética a menudo queda subordinado a los otros artificios que generan la intriga, como en el caso del ocultamiento o la confusión de identidad por medios escenográficos: la alacena (La dama duende), el pasaje se-

${ }^{20}$ Neumeister, 2011, pp. 271-274.

21 Calderón, Los alimentos del hombre, vv. 1617-1620.

22 Calderón, La humildad coronada de las plantas, vv. 1150 y 1154.

23 Calderón, Llamados y escogidos, ed. Arellano y Galván, pp. 57-58, nota al v. 95.

24 Calderón, La cena de Baltasar, vv. 891 acot. y 892-895.

25 Calderón, Lo que va del hombre a Dios, vv. 987 acot. y 988-990.

26 Calderón, No hay instante sin milagro, vv. 1472-1476.

27 Calderón, El santo rey don Fernando, primera parte, vv. 1647-1652.

28 Calderón, La nave del mercader, vv. 2344-2345.

${ }^{29}$ Calderón, El mágico prodigioso, II, vv. 1022-1025. 
creto (El galán fantasma) o el acceso por dos calles distintas (Casa con dos puertas). Aquí, el papel es un motivo más que no competirá con otros recursos de mayor impacto visual, como la escenografía complicada y el enredo espacial de La dama duende. El billete, rotulado «nadie me abra, porque soy / de don Manuel solamente», se deja durante la primera jornada para avisar al huésped de su paso por la habitación ${ }^{30}$; el papel de respuesta, a imitación de la caballería andante, sólo refleja desconcierto y una buena voluntad ${ }^{31}$; la nueva respuesta de la dama duende ofrece más pistas sobre su persona ${ }^{32}$ y el último papel sirve para citar a don Manuel en el cementerio ${ }^{33}$. Las cartas cruzadas no crean un enigma ni resuelven otro; su función, reflejo de las prácticas coetáneas, consiste en permitir que los personajes mantengan una comunicación entre ellos. Lo mismo puede decirse para Casa con dos puertas mala, es de guardar, donde el papel apenas aparece referido en su función pragmática, un mero trámite para conseguir una cita ${ }^{34}$. En el caso de El galán fantasma, Enrique y su hija entran a escena leyendo un papel; Laura indica que fue entregado por una tapada y Enrique muestra cierta preocupación. El texto, sin embargo, no genera ninguna intriga una vez que se lee: se trata de una advertencia sobre la seguridad de Astolfo cuya intención mimética es la de avisar de tal peligro y nada más 35 .

El papel anónimo, cuya autoría se intentará develar a lo largo de la comedia, es otro mecanismo que suele funcionar subordinadamente a los indicios de una identidad ocultada, al estilo de los escondidos o las tapadas; en Mañanas de abril y mayo, la carta que prepara doña Clara en la segunda jornada no hace sino continuar el enigma que ha alentado como tapada en la primera; la entrega del papel dura algunos ver$\operatorname{sos}^{36}$ y su lectura en escena despierta curiosidad por el remitente, la dama $m u d a^{37}$; la confusión de identidad se reparte, claro, entre el dis-

30 Calderón, La dama duende, I, vv. 939, 962-968 y 1079-1084.

31 Calderón, La dama duende, II, v. 22 acot.

32 Calderón, La dama duende, II, v. 603 acot.

33 Calderón, La dama duende, III, vv. 14-21.

34 Calderón, Casa con dos puertas, mala es de guardar, II, 159-164, 215-218 y 719727.

35 Calderón, El galán fantasma, I, vv. 604 acot. y 605-636.

36 Calderón, Mañanas de abril y mayo, II, vv. 48-64 y 226-269.

37 Calderón, Mañanas de abril y mayo, II, v. 269 acot. 
fraz de tapada y el papel con remitente disimulado. En el caso de la función mimética de la comunicación escrita, estudiada por Sebastian Neumeister, la independencia que tiene la carta de su marco de comunicación original ofrece distintas variantes que pueden confluir en una intriga, según diferentes combinaciones: comunicación lograda / comunicación malograda / comunicación impedida; destinatario correcto / destinatario equivocado; interpretación correcta de sus contenidos / interpretación errónea (y, como señala Neumeister, «incluso invita a los abusos» $\left.{ }^{38}\right)$. Con estas posibilidades juega Fabio cuando intenta explicar el origen de los papeles que recibe Federico en El secreto a voces («Si recibe algún papel, / no vemos quién se le da, / ni sabemos con quién va, / si acaso le escribe él $\left.\aleph^{39}\right)$. En su función mimética estricta, sin embargo, el papel poco más dice fuera de servir de intermediario. Tal como sucede con la carta de El escondido y la tapada, en Bien vengas mal el papel es un objeto material (los papeles que doña María confía a doña Ana) ${ }^{40}$, correo (el papel que manda Juan de Lara a Bernardo para citarlo y ponerlo al tanto del lance del día anterior) ${ }^{41}$ y evidencia (la carta soneto y el retrato, aunque la carta parece más bien subordinada al retrato ${ }^{42}$. En su marco mimético, sólo parece importar el efecto de realidad que la carta puede crear en el espectador.

En su función dramática, la comunicación escrita resulta fundamental en la construcción de la intriga durante amplias secciones de la comedia. La forma más obvia de uso resulta, por supuesto, el papel con función prologal: aquel cuya lectura en escena informa al público (y a los personajes) sobre la situación dramática. Por ahí empieza, por ejemplo, Calderón en su primera incursión en el género, con Hombre pobre todo es trazas, de 1627, cuando don Diego lee en escena el papel que acompaña la carta escrita para él por su propio padre. La inexperiencia del entonces joven comediógrafo le sugiere plantear la situación dramática según una doble exposición yuxtapuesta: (1) don Diego se encuentra en Madrid con su criado y, para exponer las razones de su venida, ofrece un elogio de la corte madrileña y la noti-

\footnotetext{
38 Neumeister, 2011, p. 275.

39 Calderón, El secreto a voces, I, vv. 730-733.

40 Calderón, Bien vengas mal, I, vv. 446-473.

41 Calderón, Bien vengas mal, I, vv. 600-693.

42 Calderón, Bien vengas mal, I, vv. 988-1005.
} 
cia de sus próximos lances amorosos: doña Clara, por su dinero, y doña Beatriz, por sus modos, y su doble identidad, pues con una será don Diego y con otra don Dionís ${ }^{43}$. El recurso espectacular para presentar esta información no deja de ser una salida fácil: el comentario metateatral. Así, dice don Diego:

Don Diego
¿No has visto en una comedia verse dos y en dos razones
hacerse mil relaciones de su gusto o su tragedia?
Pues imitemos aquí su estilo, que en esta parte tengo mucho que contarte ${ }^{44}$.

La corte madrileña, confusa y propicia para estos engaños, según su criado $^{45}$, parece impulsar al personaje, pero su freno se presenta en la segunda parte de la situación: (2) una carta formal, en un pliego, que envía su padre a don Luis de Toledo y una letra de cambio ${ }^{46}$; estos documentos formales se acompañan de un billete (sin denominación explícita) que el personaje lee en escena y por el que de manera simultánea se explica el título de la comedia y se suministra una causa poderosa para el enredo: «Hijo, yo no tengo hacienda para sustentar vuestras travesuras y bellaquerías. Ahí va una letra de 400 reales. Mirad cómo gastáis, que quizá no podré enviaros otra. En la Corte estáis; dad alguna traza de vivir honradamente y ved que el pobre todo es trazas ${ }^{47}$. Aunque dentro de la trama el billete no hace sino frustrar las expectativas de don Diego (no esperaba menos de mil ducados), la falta de recursos económicos servirá como una justificación para los enredos posteriores (entre otros, convertirá estos cuatrocientos reales en cuatro mil), aunque el billete por sí mismo no genere ningún enredo (y sí lo generará, por ejemplo, la letra de cambio).

Calderón volverá a aprovechar el recurso del papel con función prologal, pero ahora como un recurso exclusivo y no accesorio, pro-

\footnotetext{
43 Calderón, Hombre pobre todo es trazas, I, vv. 1-218.

${ }^{44}$ Calderón, Hombre pobre todo es trazas, I, vv. 40-46.

45 Calderón, Hombre pobre todo es trazas, I, vv. 219-231.

46 Calderón, Hombre pobre todo es trazas, I, vv. 248-251.

47 Calderón, Hombre pobre todo es trazas, I, v. 267.
} 
tagónico por lo menos en la primera jornada, en Con quien vengo, vengo, de 1630. Pese a la proximidad temporal con Hombre pobre todo es trazas, se advierte cierta madurez en la construcción del recurso. Ahora, el papel sirve para llamar la atención de los espectadores y generar un suspenso dramático sobre los contenidos que transmite: las hermanas salen a escena "asidas de un papel», forcejean por él hasta que Lisarda lo arrebata y lo lee; el público se entera de que Leonor cita a don Juan en su jardín, a espaldas de su hermano y de la misma Lisarda; esta información da pie a doña Leonor para contar sus amores con don Juan durante los últimos dos años y recibir, con ello, la ayuda de Lisarda como tercera ${ }^{48}$. La relevancia del papel en la trama no se oculta, a diferencia de Hombre pobre todo es trazas, pues Lisarda clausura este primer nudo al decir «Envía, pues, el papel, / y empiece el engaño hoy». El engaño se dilatará con acierto para el interesado público que espera su entrega expedita: primero, mientras Celio y Lisarda fingen no saber nada del papel y lo mudan en libranza, luego cuando Celio se topa al salir con don Sancho; se interpone una larga conversación entre don Juan y Otavio a la que se agrega Ursino; ante la presencia de Ursino, viejo, Celio no atina sino a esconder el papel. Al salir Ursino y entregar su papel, Celio se permite un comentario que explicita las intenciones retardatorias del dramaturgo («Leed primero el papel, / que buenas nuevas no creo / que es bien, don Juan, dilatarlas» ${ }^{49}$ ). Don Juan lee en silencio y recuerda los pormenores de sus amores con Lisarda; la lectura del mismo papel por don Otavio permite crear una situación refleja de la tercería de Leonor: Otavio se disfrazará de criado (imitando la particular forma de hablar de Celio) para ayudar en este lance a su amigo don Juan ${ }^{50}$. El papel del inicio da de sí para presentar los antecedentes del caso, para conformar la trama secundaria (Lisarda y Otavio, mudadas sus identidades), crear cierto suspenso dramático sobre el contenido de la carta y, una vez develado, un suspenso aún mayor por la entrega diferida una y otra vez con algo de humor.

En Con quien vengo, vengo, el papel es una columna vertebral que, de acuerdo a la variatio de la época, se presenta con dos perfiles muy

48 Calderón, Con quien vengo, vengo, I, vv. 1-210.

${ }^{49}$ Calderón, Con quien vengo, vengo, I, vv. 812-814.

50 Calderón, Con quien vengo, vengo, I, vv. 211-1229. 
distintos. Así, la función prologal del papel en la primera jornada da paso, durante la tercera jornada, a otra función: el papel como auxiliar en la construcción del suspenso o tensión dramática producido por la presentación de un enigma y la dilatación del proceso de resolución. Se puede advertir que la construcción del suspenso dramático en varios niveles y desde diferentes perspectivas se repite en la tercera jornada, también con buena dosis de tensión dramática, cuando se desarrolla esta secuencia en las siguientes partes: (1) Ursino y su criado espían a don Sancho y lo ven escribiendo un papel. (2) Sancho pone en antecedentes a Ursino, sin conocer que es padre de don Juan. (3) Sancho le avisa que lo escrito por él es un cartel de desafio (nombrado siempre papel). A partir de aquí, las siguientes acciones sirven para diferir la resolución del enigma: (4) Sancho y Ursino descubren que la hermana en custodia es Lisarda y no Leonor, con la consiguiente sorpresa. (5) Sancho pide a Ursino que busque a quien dice en el papel y lo entregue. (6) Ursino se queda solo, lee el papel y descubre con sorpresa que es un desafio para don Juan. (7) Ursino presenta el caso moral: «Si doy a mi hijo el papel, / cierto su riesgo será; / si no, don Sancho dirá / que es cobarde: ¡qué cruel / duda padezco!». En esta sección, el personaje recuerda el dilema moral o enigma planteado al principio, de modo que su intervención puede considerarse una reiteración de los puntos 2 y 3 ; no hay que perder de vista, sin embargo, que la repetición permite aclarar al público los aspectos principales de la trama y, al mismo tiempo, cumple con la función de retrasar el desenlace; por otro lado, intensifica la tensión dramática. (8) La secuencia no termina aquí, porque luego Ursino dará algunos rodeos para entregar el papel a don Juan, su hijo (contará que lo trajo un criado, que se trata de una cobranza y que no ha visto su contenido para no pagar porte). (9) Finalmente, don Juan lee el billete donde don Sancho lo reta y se lamenta de haberlo leído en voz alta, pues ahora ha involucrado de nuevo a don Otavio por esta indiscreción ${ }^{51}$. Si el público ha estado en suspenso hasta este momento sobre el contenido de la carta de desafio, no descansará después; (10) Ursino contará a Sancho que ha cumplido con entregar el desafío y que como padrino lo acompañará al duelo; (11) ahí, padre e hijo colocan su honor por encima de los lazos de sangre y se arma la batalla. En el clí-

51 Calderón, Con quien vengo, vengo, III, vv. 688-958. 
max de este lance, aparecen Lisarda, Leonor, Celio, el gobernador y más gente para solucionar el conflicto con un doble casamiento ${ }^{52}$. El papel, muy lejos de ser un medio de comunicación para proveer información económica y expedita al espectador (impresión que tenemos al principio de la comedia, cuando salen Lisarda y Leonor asidas al papel), se enriquece de forma paulatina gracias a los diálogos y acciones de los personajes hasta transformarse en un efectivo mecanismo de suspense que mantendría atento e interesado al público en una trama con un final predecible, pero sistemáticamente diferido por medio del artificio.

Esta particular forma de suspense se repetirá, con una construcción más compleja, en No hay burlas con el amor, de hacia 1637 y la última del periodo estudiado. Ahí, la lucha de dos personajes por un papel, sin función prologal, aumenta a tres involucrados; inicia con Leonor y Beatriz también asidas a un papel, como en Con quien vengo, vengo, pero concluye de forma sorpresiva con la llegada de su padre:

$$
\text { Ásela del papel y porfían las dos. }
$$

Beatriz Suelta la epístola.

INÉS

No es sino Evangelio.

LEONOR

Aunque intentes

por fuerza verle, tirana, poco podré o no has de verle.

BeAtriz Deja el papel...

Sale don Pedro y rompen el papel, quedándose con la mitad cada una.

Don Pedro

¿Qué papel

es? ¿por qué reñis, aleves?

INÉS

¡Cayóse la casa, como dice el fullero que pierde!

Don Pedro Suelta este pedazo tú y tú suelta esotro ${ }^{53}$.

52 Calderón, Con quien vengo, vengo, III, vv. 991-1192. 
Como ha señalado Neumeister al analizar este mismo episodio, «la disputa desemboca [...] en la destrucción del objeto en cuestión sin que puedan enterarse de lo que contiene ni las protagonistas ni los espectadores de la comedia. Aún peor, la carta llega a manos de un destinatario equivocado, en este caso el menos deseable posible: el padre de las dos hermanas ${ }^{54}$. Neumeister se fija demasiado, en mi opinión, en la función mimética del papel (transmitir un comunicado), pero pasa por alto su función dramática: despertar la curiosidad del público, quien comparte la perspectiva de los personajes desde múltiples ángulos. El público sabe, por ejemplo, que don Juan le ha contado a don Alonso su temor de haber sido visto por Beatriz mientras se entrevistaba con Leonor en su balcón, por lo que ha preparado una carta (la de la disputa anterior):

Don Juan $\quad[.$.$] porque si acaso ha llegado$
a su noticia mi intento,
la vida del dueño mío
no dudo que corra riesgo.
Y así, porque en ir o estarme
hay peligro, elijo un medio
que es enviar este papel
disimulado y secreto,
que aun no va de letra mía,
para cuyo efecto quiero
a Moscatel, que le lleve,
valiéndose de su ingenio
y se le dé a Inés, criada
de Leonor, porque no siendo
conocido por criado
mío, no hay que tener miedo ${ }^{55}$.

El contenido de este papel, sin remitente, escrito por otro que el propio don Juan y enviado con un mozo ajeno y recibido por la criada de Leonor, es del todo previsible, como nos hace saber aquí mismo don Juan ("porque si acaso ha llegado / a su noticia mi intento, /la vida del dueño mío / no dudo que corra riesgo") y versos des-

\footnotetext{
53 Calderón, No hay burlas con el amor, I, vv. 870 acot. y 871-881.

54 Neumeister, 2011, pp. 269-270.

55 Calderón, No hay burlas con el amor, I, vv. 310-325.
} 
pués («porque si llego / a saber que está Leonor / en peligro, estoy resuelto / a sacarla de su casa / aunque todo el Mundo entero / lo estorbe» ${ }^{56}$ ) y confirma más adelante la misma Leonor cuando decide contestar su papel sin haberlo leído («dame el papel porque quiero / al instante responderle / a don Juan en el peligro / que estoy ${ }^{57}$ ). Todo esto lo ignora don Pedro cuando interroga a las dos hermanas sobre el mensaje y ambas confiesan no saberlo ${ }^{58}$; pero al salir ambas de escena don Pedro pide a Inés que testifique no sobre el contenido, sino sobre la propiedad del papel, pues Leonor se ha defendido diciendo que era de su hermana y Beatriz, al contrario, ha dicho la verdad. La situación, ambas asidas del papel, no permite advertir quién sea su verdadera dueña y el interrogatorio a Inés no despeja las dudas del personaje, pues ella avisa que llegó poco antes que don Pedro (aunque sabe que pertenece a Leonor $)^{59}$. Don Pedro juntará los pedazos «desta víbora, esta sierpe, / que dividido el veneno / en dos mitades contiene» y leerá el papel como cierre de la jornada:

\section{Lee.}

Mal podré, hermoso dueño, decirte ni encarecerte el cuidado con que estoy de que anoche nos oyese tu hermana. Avísame al punto que a tu padre se lo cuente, para que te ponga en salvo ${ }^{60}$.

El contenido de la carta es el esperado por el público, pero la verdadera función consiste en expresar su contenido sin aclarar a quién se dirige, de modo que don Pedro habrá de confesar:

Don Pedro A entrambas a dos conviene el papel, para que sea hoy mi desdicha más fuerte; pues si supiera de una

56 Calderón, No hay burlas con el amor, I, vv. 329-334.

57 Calderón, No hay burlas con el amor, I, vv. 824-827.

58 Calderón, No hay burlas con el amor, I, vv. 885-946.

${ }^{59}$ Calderón, No hay burlas con el amor, I, vv. 948-970.

${ }^{60}$ Calderón, No hay burlas con el amor, I, vv. 977-983. 
que con liviandad procede, supiera también de otra la virtud... y desta suerte templado estuviera el daño ${ }^{61}$.

Esta primera jornada cierra con un enigma para don Pedro, pero no para el público. Al inicio de la segunda jornada, cuando don Juan y Leonor se entrevistan, recordarán el tema (dice Leonor de su padre "que hasta aquí no ha sabido / cúyo el papel ni para quién ha sido»62; don Juan también confirma los detalles de la redacción que permitían atribuir el mensaje a cualquiera de las dos hermanas: «Dicha fue que viniera / el papel de manera / que a entrambas convenía, / que bien se acuerda la memoria mía / de que no te nombraba / y de que escrito de otra letra estaba» $\left.{ }^{63}\right)$. Cuando don Pedro vuelve a escena, lo hace escondido («al paño») para espiar una conversación entre Leonor y Beatriz; advertida Leonor de su presencia, guía la conversación a su favor hasta convencer a don Pedro de que "Leonor es la virtuosa» ${ }^{64}$. Don Alonso, por consejo de Leonor y en su beneficio, aprovechará el mismo billete equívoco para engañar a Beatriz, apoyado por Inés, al hacerle creer que el papel por el que han reñido en la jornada primera era para ella, traído por su criado, recibido por Inés y arrebatado por equivocación por Leonor de sus manos (lo que Inés confirma). El poder de esta carta se extenderá incluso hasta la tercera jornada, donde se recomponen las parejas: don Alonso se enamora del buen trato de Beatriz (agradecida a causa del papel inicial) y don Juan riñe por celos a doña Leonor; Beatriz, al paño, se entera de todo el enredo previo; don Pedro (que sigue sin conocer al destinatario del papel) ofrece la mano de Beatriz a quien cree su pretendiente, pero al ser rechazado, intenta cobrar su honor; al final, en duelo con don Diego y don Luis, se arman las parejas correspondientes: Beatriz y Alonso, Leonor y Juan e Inés y Moscatel. Don Pedro no despeja la incógnita planteada por la carta en toda la obra, pero recibe un final satisfactorio cuando don Juan y don Alonso se ofrecen a luchar contra don Luis, quien ha deshonrado a don Pedro. La complejidad de una sola carta alcan-

61 Calderón, No hay burlas con el amor, I, vv. 984-991.

62 Calderón, No hay burlas con el amor, II, vv. 230-231.

63 Calderón, No hay burlas con el amor, II, vv. 239-244.

64 Calderón, No hay burlas con el amor, II, vv. 327 acot., 328-348. 
za hasta el desenlace de la obra y su confección con destinatario y remitente anónimos permite que se adapte sin dificultad a distintas circunstancias comunicativas.

La importancia de la carta como rasgo definitorio de la comedia de capa y espada en Calderón provoca que el estudio de este recurso sea inabarcable a ratos. En todo caso, empezar a definir sus características y sus desarrollos nos pone en el mejor camino para entender sus principales funciones. Se trata, como escribió el mismo Calderón hacia 1648-1650, de otro de los lugares comunes de la comedia de capa y espada que no podemos obviar sin ser infieles a la particular naturaleza de este tipo de comedias:

DON JUAN

Empecé su galanteo con buena fortuna y mala, y paseando los comunes lugares (papel, criada, reja y noche, girasol de puertas y de ventanas) a poca costa de penas, a poco gasto de ansias, merecí que de favores coronase mi esperanza, dándome, a riesgo del padre, en su mismo cuarto entrada una noche. 


\section{BiBLIOGRAFÍA}

Arellano, I., El escenario cósmico. Estudios sobre la comedia de Calderón, Madrid / Frankfurt, Iberoamericana / Vervuert, 2006.

Calderón de la Barca, P., Llamados y escogidos, ed. I. Arellano y L. Galván, Kassel / Pamplona, Reichenberger / Universidad de Navarra, 2002.

EsCAlonilla LóPEZ, R. A., «El paradigma de la caricatura quijotesco-cervantina en el teatro de Calderón», Epos, 18, 2002, pp. 145-161.

Neumeister, S., «Funciones y avatares de la carta en las comedias de Calderón», Anuario Calderoniano, 4, 2011, pp. 263-281.

Simón Palmer, M. ${ }^{a}$ del C. (dir.), Teatro Español del Siglo de Oro 3.0, CDRom, España, Chadwick-Healy, 1997-1998. 